\title{
Biobased Resources and Value Chains
}

\author{
Christian Zörb, Iris Lewandowski, Ralf Kindervater, \\ Ursula Göttert, and Dominik Patzelt
}

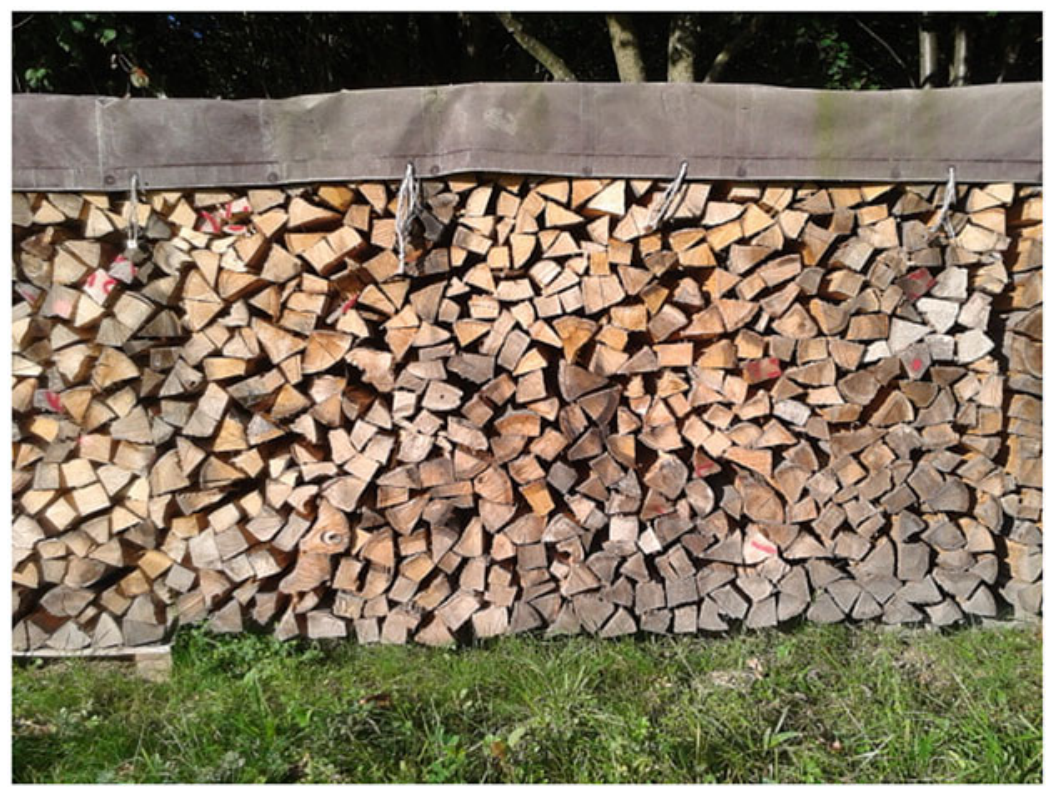

(C) Ulrich Schmidt

The original online version of this chapter was revised. An erratum to this chapter can be found at https://doi.org/ 10.1007/978-3-319-68152-8_13.

Individual section's authors are indicated on the corresponding sections.

C. Zörb $(\bowtie)$

Institute of Crop Science; Quality of Plant Products, University of Hohenheim, Stuttgart, Germany

e-mail: christian.zoerb@uni-hohenheim.de

\section{Lewandowski}

Institute of Crop Science; Biobased Products and Energy Crops, University of Hohenheim, Stuttgart, Germany e-mail: iris_lewandowski@uni-hohenheim.de

R. Kindervater • U. Göttert • D. Patzelt BIOPRO Baden-Württemberg GmbH, Stuttgart, Germany

e-mail: kindervater@bio-pro.de; goettert@bio-pro.de; patzelt@bio-pro.de 
The bioeconomy uses the resources biomassoriginating directly or indirectly from plants, microorganisms or animals - and biological knowledge. A bioeconomist requires knowledge of these resources to be able to plan the resource supply strategy for a bioeconomic activity, to decide which biomass resource is best suited for a specific biobased product chain and how these product chains can be optimized. This chapter describes the characteristics of biomass, important techno- logies for the designing of these characteristics and the use of data and biological knowledge.

In the second part of the chapter, the concept of biobased value chains and their integration into value nets is addressed. Examples of value chains from food, bioenergy, biomaterial and biochemical applications are used to demonstrate how biomass is integrated into different biobased product chains. 


\subsection{Biobased Resources}

Christian Zörb and Iris Lewandowski

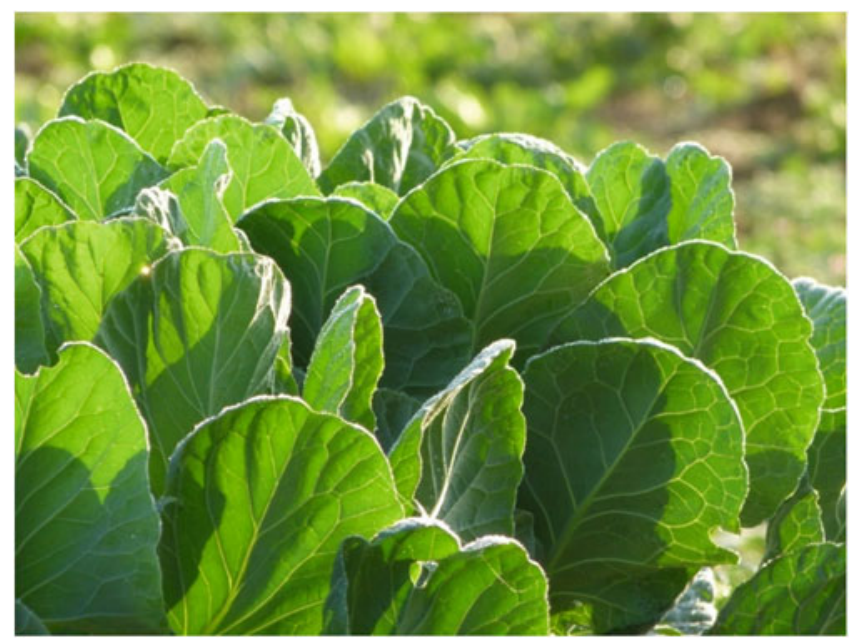

(C) Ulrich Schmidt

Abstract Biobased resources are all resources containing non-fossil, organic carbon, recently ( $<100$ years) derived from living plants, animals, algae, microorganisms or organic waste streams. These are summarized in the term "biomass". This section describes the formation of biomass through the process of photosynthesis. Biobased resources can be classified and characterized according to their origin (e.g. plant, animal) and the sector (agriculture, forestry or waste) in which they are produced. However, for the integration into specific biobased product chains, the most relevant classification of biomass is according to its major component, i.e. starch, sugar, lignocellulose, oil or protein.

There are various options for tailoring biomass properties to user demands. This section considers breeding, green biotechnology and genetic engineering. Synthetic biology uses the tools of genetic engineering and biotechnology to construct completely new functional units or systems with desired properties. The bioeconomy also makes use of biological knowledge, described here as the combination of biological data and its interpretation, often by means of bioinformatics, and the understanding of naturally occurring mechanisms (bionics).

Keywords Biomass; Biomass production; Biobased resources; Biomass use; Plant modification

\section{Learning Objectives}

After studying this chapter, you should:

- Understand the process of biomass formation.

- Be able to characterize the resource base of the bioeconomy.

- Have gained an overview of techniques to design biomass characteristics.

- Understand the concept of biological knowledge.

\section{Biomass Concepts: Different Perspectives}

The concept of biomass was introduced in the year 1927 by a publication of the German zoologist Reinhard Demoll (1882-1960): "By biomass we term the quantity of substance in living organisms 
per unit of surface or volume" (Demoll 1927). Currently, there is no consensus on the general definition of "biomass". A simple and widely used biological definition is "organic matter derived from living, or recently living organisms". This definition may be too broad to be of use as an exact definition for this bioeconomy textbook. Let us focus on different perspectives of what constitutes biomass. Even in ecology, there is no standard definition of biomass. One reason is that biomass changes as organisms interact with each other and with their abiotic environment. Instead, a colourful variety of ecological biomass concepts exists side by side.

\section{A Biologist's Perspective}

When considering the term "biomass", a biologist would first think of carbohydrates (e.g. starch, sugar), proteins (e.g. storage proteins from grains), fats and oils (e.g. from oil seeds) and other secondary plant compounds. These substances are secondary metabolites of (plant) tissue, many examples of which can be found in biochemistry textbooks. Primary plant metabolites are compounds produced from the sugars formed by photosynthesis and used for metabolism. By contrast, secondary metabolites are not involved in primary metabolism but are responsible, for example, for the structure and functioning of a cell or organism. Higher plants probably build around 100,000-150,000 different secondary compounds including a diverse range of proteins, sugars, sugar alcohols, vitamins, fats, oils, amino acids, organic acids, nucleic acids, phenolic compounds, odours, pigments, etc. There are many interesting substances within these classes that may be (re) discovered in the bioeconomy as valuable compounds for polymer chemistry or possibly even pharmacy.

\section{A Chemist's Perspective}

A chemist would like to see a molecular formula to describe carbohydrates, proteins, fats and other secondary substances showing the chemical elements incorporated by autotrophs (see Fig. 5.1 and section "Photosynthesis") together with an amount of binding energy. However, unfortunately, there is no chemical formula for the general definition of biomass. Physicists or agronomists may calculate the energy value of a certain biomass fraction, from a maize field, for example, using an equation for the heating value of biomass based on its components, but this is also only part of the "what is biomass" story.

\section{A Technologist's Perspective}

Technologists see biomass as a source of energy. Therefore, they mostly think of plant-based materials not used for food or feed applications, specifically lignocellulosic biomass. Although technical biomass definitions include only biotic substances that can be used as energy sources, a number of different energy-related biomass terms and definitions still exist. Biomass can be used for energy either directly via combustion to produce heat or indirectly after conversion to various forms of biofuel. There are several methods of converting biomass into biofuels, and these are broadly classified into thermal, chemical and biochemical methods (see Chap. 7 for description of conversion technologies).

\section{Our Definition of Biomass}

In Sect. 2.2, biobased resources were defined as all resources containing non-fossil, organic carbon, recently ( $<100$ years) derived from living plants, animals, algae, microorganisms or organic waste streams. These are summarized in the term "biomass". Biomass can be further defined as plant or animal tissue or tissue-based material, microorganisms and the substances produced from them as well as organic molecules (primarily) formed by (photosynthetic) organisms such as carbohydrates (e.g. sugars), proteins, fats, fibre, vitamins and other secondary plant metabolites. This includes edible biomass, such as starch-, sugar- and oil-rich biomass and nonedible lignocellulosic biomass from dedicated crop production, residues and organic wastes. Today, the term "biomass" is most frequently used to refer to organic material utilized for energy production and other nonfood applications such as the production of biogenic 
materials and chemicals. In the following text, we use a more general definition of biomass, which includes edible as well as nonedible organic material.

\subsubsection{Biomass: Its Origin and Characterization}

\section{Photosynthesis}

Primary production is the process that directly or indirectly supports virtually all life on Earth. Primary biomass is formed by the conversion of carbon dioxide $\left(\mathrm{CO}_{2}\right)$ and water through the autotrophic processes of photosynthesis (performed by plants and green algae) and chemosynthesis (performed by some microorganisms). Of these two processes, photosynthesis is the more important. In this process, autotrophic organisms take up $\mathrm{CO}_{2}$ and water and convert them into carbohydrates with the help of light energy (photons). Thus, light energy is converted into chemical energy through the integration of carbon $(\mathrm{C})$ into the organism's substance (assimilation). The final products of photosynthesis are C6 sugars (hexoses) and oxygen. Figure 5.1 shows the chemical equation summarizing the complete process.

Glucose is used as a resource in internal plant biochemical processes to form various other molecules through subsequent biochemical reactions, which also incorporate macro- and micronutrient elements into the plant substance. It is estimated that plants can build up around 100,000-150,000 different chemical substances, many of which have not yet been identified but could be interesting in a future bioeconomy. However, not all of these substances are available in sufficiently high quantities or concentrations.

$$
6 \mathrm{CO}_{2}+6 \mathrm{H}_{2} \mathrm{O} \underset{\text { Chlorophyll }}{\stackrel{\text { Light }}{\rightarrow}} \mathrm{C}_{6} \mathrm{H}_{12} \mathrm{O}_{6}+6 \mathrm{O}_{2}
$$

$\mathrm{CO}_{2}$ : carbon dioxide; $\mathrm{H}_{2} \mathrm{O}$ : water; $\mathrm{C}_{6} \mathrm{H}_{12} \mathrm{O}_{6}$ : glucose

Fig. 5.1 Photosynthesis
Biotechnological methods may make it possible to increase the production and concentration of target molecules by plants and microorganisms.

The first step in biomass formation is the absorption of light by the chlorophyll molecule. Photosynthetic electrons are used for the assimilation of $\mathrm{CO}_{2}$ and the formation of carbohydrates such as sugars in plant cells. However, not all absorbed energy electrons can be converted to chemical energy in the form of sugars. There are energy losses in the process of photosynthesis, for example, the heat produced by metabolism, and energy consumption through photorespiration and other processes such as the Mehler reaction (for further information, see Taiz et al. 2015). Therefore, the maximal efficiency of photosynthesis is estimated to be about $12 \%$. However, this is a theoretical maximum (Radmer and Kok 1977) that can never be achieved by a growing crop, even if all adverse factors such as disease, predation, inadequate inorganic nutrient supply and suboptimal water supply are mitigated. Wilhelm and Selmar (2011) calculated a conversion efficiency of photosynthetic energy into biomass of only about $8 \%$ (Fig. 5.2).

Given the above-mentioned energy losses in biomass formation, it is of vital importance that available biomass is used as efficiently as possible. Here, three approaches for efficient biomass production and use are suggested:

- Focusing on the production of valuable (biochemical) substances by plants and algae. An effective strategy would be the production of valuable organic substances (such as glycolate, omega-3 fatty acids, lutein) by algae. Microalgae in particular have a higher photosynthetic efficiency because the light absorption of small algal cells (unicellular algae) is generally better than that of larger algae.

- Supporting the efficiency of crop production through optimal crop management, improved harvest technologies and the avoidance of biomass losses in the supply chain (see Sect. 6.1).

- Applying breeding and biotechnological methods to supply varieties that make optimal 
Fig. 5.2 Energy balance of biomass production. Bars represent photosynthetic energy absorbed and the various energy losses by transformation into biomass. Hundred percent is the maximum photosynthetic active energy (based on Wilhelm and Selmar 2011)

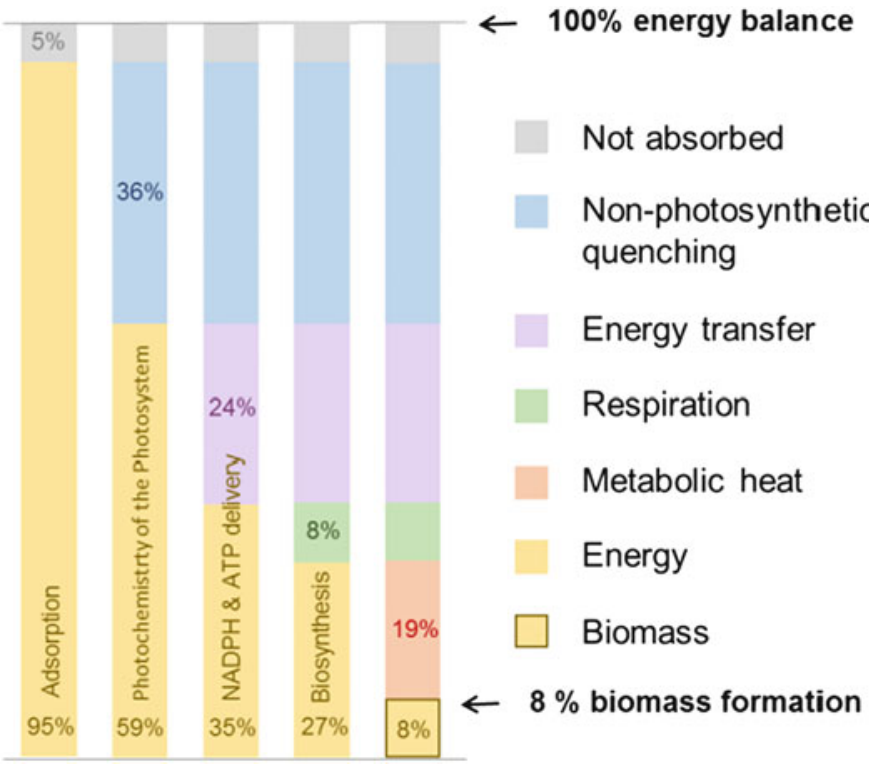

use of factors necessary for growth and that are tailored to the production of specific products (e.g. metabolites, proteins) at high concentrations in the biomass.

All biological material (or biomass) is essentially derived from inorganic molecules or ions that are assimilated into the biological tissue of autotrophic (primary) organisms (plants and microorganisms) through photosynthetic or chemosynthetic processes. Organisms that perform primary production are called "autotrophs" because they are self-feeding and use light as an energy source. In the process of photosynthesis, they take up $\mathrm{CO}_{2}$ and convert it into chemical energy with the help of sunlight. These organisms provide the basis for secondary biological organisms, i.e. heterotrophs. Heterotrophs (animals, humans, fungi, most bacteria) rely on the consumption of either the products of autotrophs or whole autotrophic organisms.

Biomass is formed primarily from carbon (C), oxygen $(\mathrm{O})$ and hydrogen $(\mathrm{H})$ (Fig. 5.1). These are assimilated from air and water. In addition, mineral macronutrients are essential for plant growth and development and thus biomass formation. The main macronutrients necessary for the production of biomass by primary organisms are nitrogen $(\mathrm{N})$, phosphorus $(\mathrm{P})$, potassium $(\mathrm{K})$, calcium $(\mathrm{Ca})$, magnesium $(\mathrm{Mg})$ and sulfur $(\mathrm{S})$. These elements are also the major components of plant fertilizers, mostly in the form of ammonium, nitrate, urea, phosphate and potassium salts. Further important elements are the so-called plant micronutrients, which are essential but only in very small quantities-mostly at concentrations three orders lower than that of macronutrients. They include iron $(\mathrm{Fe})$, manganese $(\mathrm{Mn})$, zinc $(\mathrm{Zn})$, copper $(\mathrm{Cu})$, boron $(\mathrm{B})$, molybdenum $(\mathrm{Mo})$, chlorine $(\mathrm{Cl})$ and nickel (Ni). Other elements that can be beneficial for plant growth in niche environments are silicon (Si), cobalt (Co), selenium (Se) and sodium (Na) (Fig. 5.3).

\section{Biomass Characterization}

Biomass resources can be classified according to their origin, i.e. whether they come from plants, animals or microorganisms. Not only the requirements for their production (see Sects. 6.1.9, 6.1.10 and 6.4) are different but also the characteristics of their products. This is not only relevant from a processing point of view but also from an ethical point of view, for example, meat is not an "acceptable" biomass for vegetarians. 


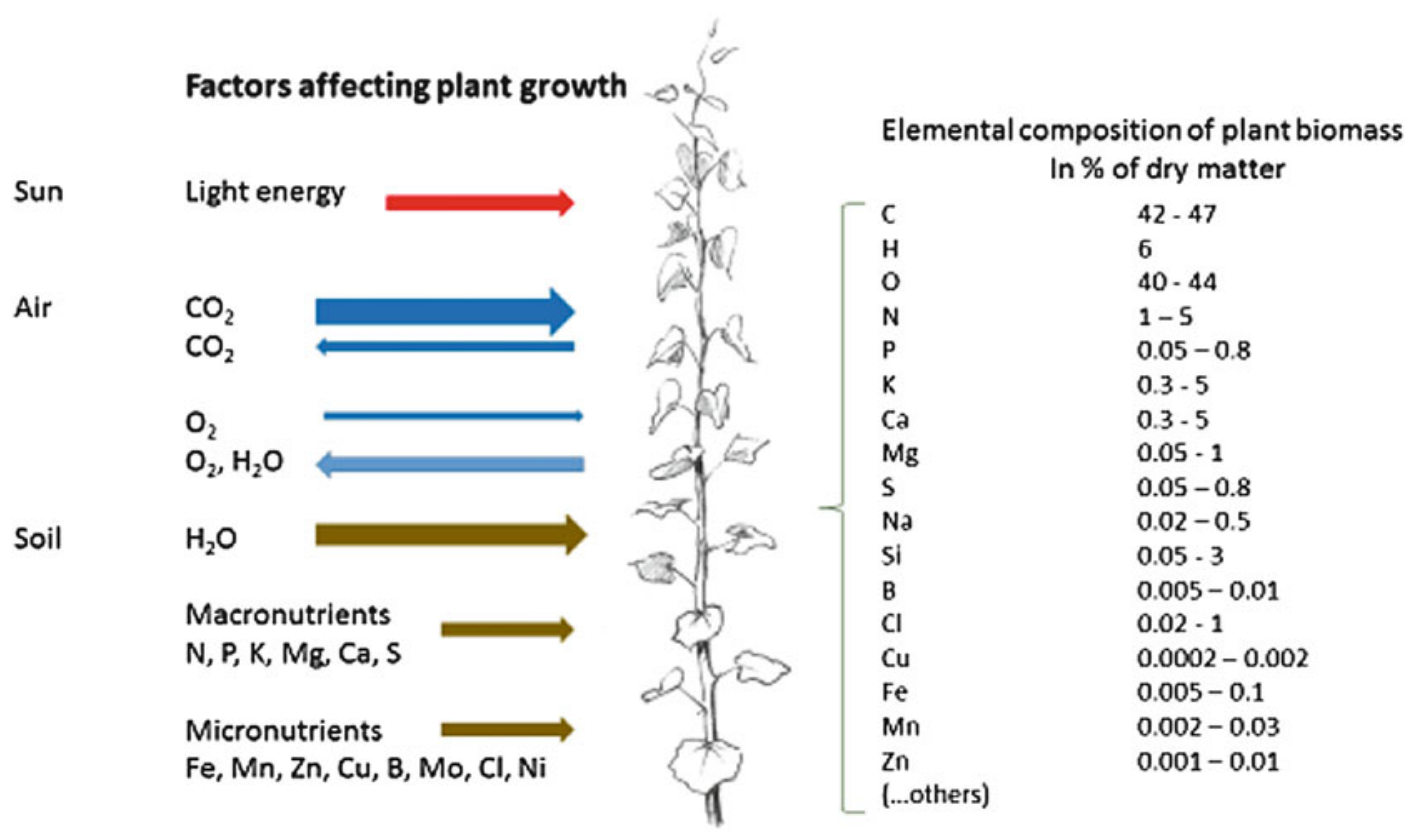

Fig. 5.3 Factors affecting plant growth and elemental composition of plant biomass (adapted from Lewandowski and Wilhelm 2016)

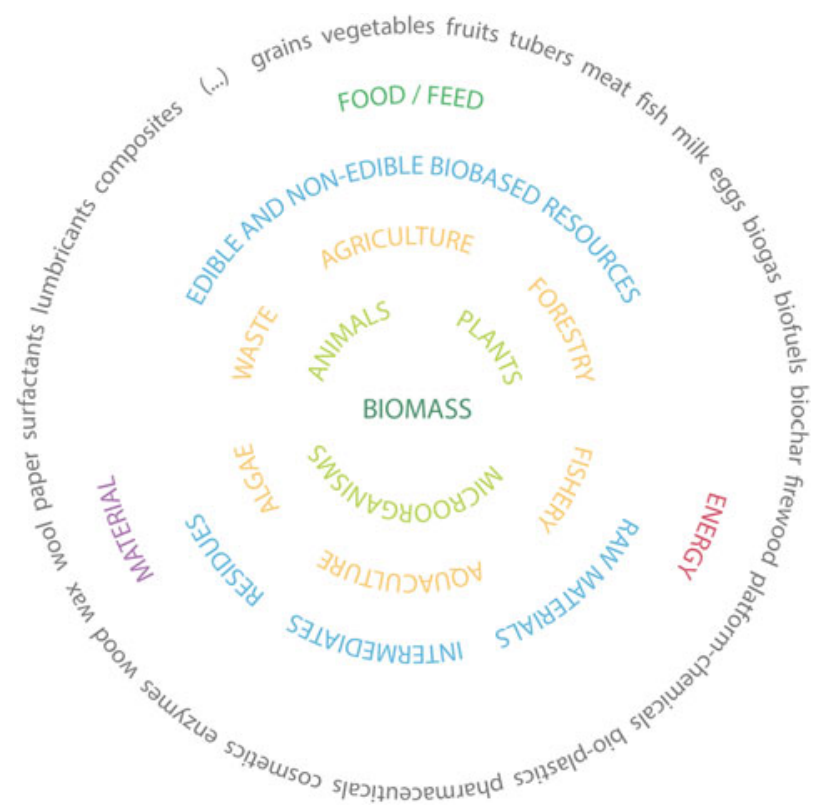

Fig. 5.4 Biobased resources. Plant, animal and microorganism biomass is produced in different primary sectors of the bioeconomy. These biomass resources are processed to food, feed, energy or raw materials. Examples of products used in the bioeconomy are seen in the outer circle 
Table 5.1 Classification criteria for biomass resources

\begin{tabular}{|c|c|c|}
\hline $\begin{array}{l}\text { Organisms which } \\
\text { produce biomass }\end{array}$ & $\begin{array}{l}\text { Sector of biomass } \\
\text { production }\end{array}$ & Major biomass components (molecular formula) \\
\hline $\begin{array}{l}\text { Plants } \\
\text { Animals } \\
\text { Microorganisms }\end{array}$ & $\begin{array}{l}\text { Agriculture } \\
\text { Forestry } \\
\text { Fishery and } \\
\text { aquaculture } \\
\text { Algae and } \\
\text { microorganisms } \\
\text { Waste }\end{array}$ & $\begin{array}{l}\text { Sugars (e.g. glucose, } \mathrm{C}_{6} \mathrm{H}_{12} \mathrm{O}_{6} \text { ) } \\
\text { Starch }\left(\mathrm{C}_{6} \mathrm{H}_{10} \mathrm{O}_{5}\right)_{n} \\
\text { Cellulose }\left(\mathrm{C}_{6} \mathrm{H}_{10} \mathrm{O}_{5}\right)_{n} \\
\text { Hemicelluloses }\left(\mathrm{e} . \mathrm{g} \text {. xylose, } \mathrm{C}_{5} \mathrm{H}_{10} \mathrm{O}_{5} \text { ) }\right. \\
\text { Lignin (coumaryl alcohol, } \mathrm{C}_{9} \mathrm{H}_{10} \mathrm{O}_{2} \text {; coniferyl alcohol, } \mathrm{C}_{10} \mathrm{H}_{12} \mathrm{O}_{3} \text {; } \\
\text { sinapyl alcohol, } \mathrm{C}_{11} \mathrm{H}_{14} \mathrm{O}_{4} \text { ) } \\
\text { Oils (triglycerides, e.g. oleic acid, } \mathrm{C}_{18} \mathrm{H}_{34} \mathrm{O}_{2} \text { ) } \\
\text { Proteins (amino acids, e.g. alanine, } \mathrm{C}_{3} \mathrm{H}_{7} \mathrm{NO}_{2} \text { ) }\end{array}$ \\
\hline
\end{tabular}

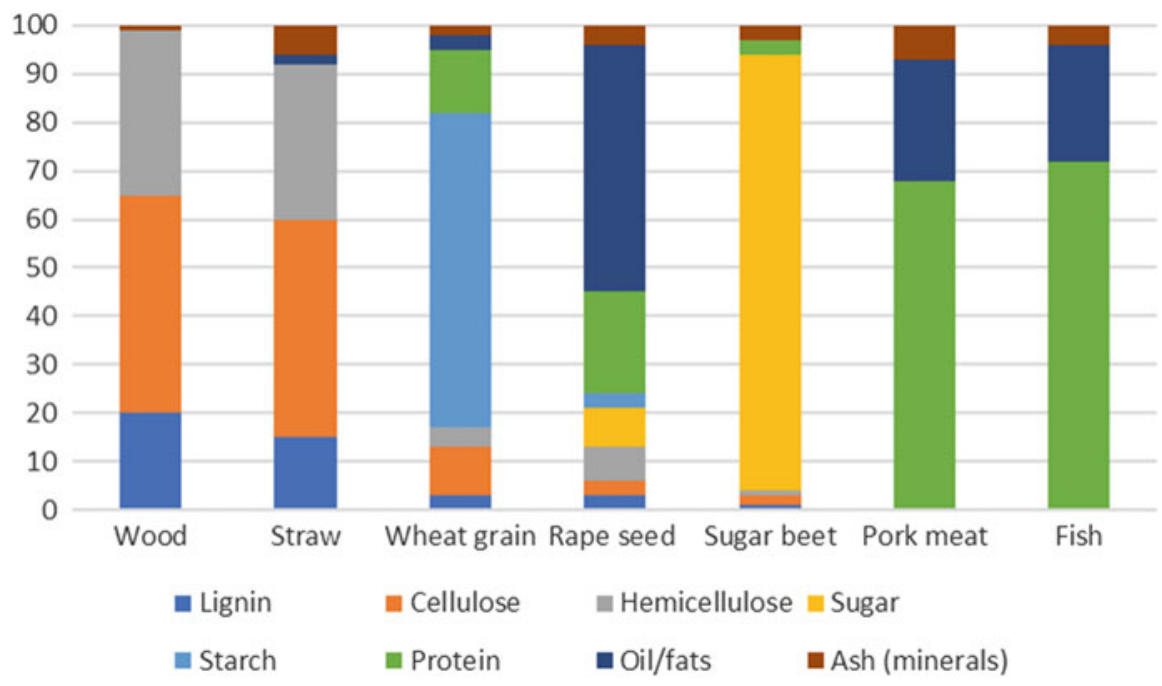

Fig. 5.5 Main components of different biomasses (in \% of dry matter)

Biomass resources can also be classified according to the sector in which they are produced, e.g. as agricultural, forestry or waste biomass (Fig. 5.4). The biomass supply chains in each sector vary from a practical point of view. But also from an ethical point of view, it makes a difference whether biomass has been classified as waste or whether it comes from the agricultural sector. The use of waste biomass is generally considered beneficial, whereas agricultural biomass has the primary task of producing food. In the latter case, a careful decision needs to be made on the best use of the biomass to avoid competition with food supply. The energetic use of edible biomass, such as vegetable oil, for the production of biofuels has received particular criticism. For this reason, biomass is also classified into "edible" and "nonedible" in terms of suitability for human consumption.

The most relevant classification of biomass for its integration into specific biobased product chains is according to its major component, i.e. starch, sugar, lignocellulose (lignin + cellulose + hemicellulose), oil or protein (Table 5.1). All of these contain mainly $\mathrm{C}, \mathrm{H}$ and $\mathrm{O}$. Only proteins, being a combination of different amino acids, also contain $\mathrm{N}$ and some contain $\mathrm{S}$ (Table 5.1).

Figure 5.5 shows the major components of different biomasses. These vary considerably between lignocellulosic biomasses (such as wood and straw), starch-rich biomasses (e.g. wheat grain), oil-rich biomasses (e.g. rape seed), sugar- 
rich biomasses (e.g. sugar beet) and protein-rich biomasses (e.g. pig meat and fish).

Finally, biomass can also be characterized according to its physical conditions into "wet" and "dry" or "solid" and "liquid" biomass. The physical properties of biomass determine the requirements for its harvest, transport, storage and processing (see Sect. 7.3). Generally, wet biomass is more perishable than dry biomass. It requires a higher transport effort (because more water is transported) and additional processing before storage, such as drying or ensiling (e.g. maize is ensiled for feed and biogas applications).

\section{Global Biomass Use}

Currently, it is estimated that about 11.4 billion tonnes of biomass are produced annually on agricultural land and from forests. Of this, $18 \%$ stems from wood, $40 \%$ from agricultural production, $30 \%$ from pasture and $12 \%$ are by-products (FAOSTAT 2014; Raschke and Carus 2012). The largest part of this biomass is comprised of cellulose (5.62 billion tonnes, 49\%). Other important biomass feedstocks are sugar/starch (2.63 billion tonnes, 23\%), protein (1.23 billion tonnes, 12\%) and fat ( 0.51 billion tonnes, $4 \%$ ) (FAOSTAT 2014; nova Institut 2015). About three quarters of the total biomass produced by agriculture is used as feed to produce 115,90 and 60 million tonnes of pig, chicken and cattle meat, respectively, and 640 million litres of milk (Fig. 5.6).

\subsubsection{Techniques for Improving or Designing Biomass Characteristics}

\section{Breeding}

Humans started to cultivate plants as they began to settle about 10,000 years ago. It was beneficial for them to have food stored throughout the whole year, to consume when less or no freshly produced food was available. This enabled them to survive in unfavourable climates where naturally grown plant-based food was only available in a particular season. Early farmers already

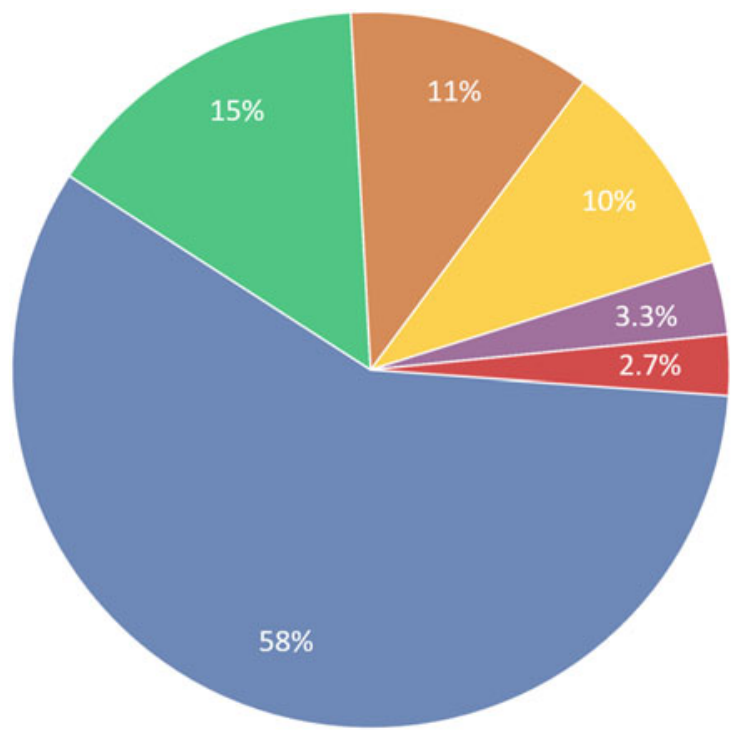

\section{Forestry biomass \\ Material use \\ Energy use}

\section{Agricultural biomass}

Material use

Energy use

Animal feed

Food

Total biomass:

ca. 11.4 billion tons

Fig. 5.6 Worldwide use of harvested forestry and agricultural biomass in 2008 (based on Raschke and Carus 2012) 
started breeding wild plants and selecting the genotypes with the best performance in terms of high yield, non-shedding seeds and resistance to biotic and abiotic stress (e.g. drought). They developed many of our most important plants, such as wheat, maize (corn), rape and rice. Today, breeding is still the most important prerequisite for sufficient and sustainable food production.

Breeding is the improvement of crop varieties and animal breeds - in terms of yield, resistance to pests and diseases, fertility, product quality or adaptation to different production conditions - through breeding methods. These are classified as either "conventional" or "genetic engineering" methods. Conventional breeding seeks to provide improved varieties or breeds by selection and directed crossing. Genetic engineering (or genetic modification) uses biotechnological techniques to alter the genome (genetic material) of the organism.

\section{Green Biotechnology}

Biotechnology is "any technological application that uses biological systems, living organisms, or derivatives thereof, to make or modify products or processes for specific use" (UN Convention on Biological Diversity, Art. 2). Green biotechnology is the application of such techniques in agricultural processes. An example is the use of genetic engineering methods to design transgenic plants able to grow in particular environments characterized by the presence (or absence) of specific (bio)chemicals.

\section{Genetic Engineering}

Genetically modified organisms (GMOs) are organisms that have had their genomes altered, either in a way that does not occur naturally or in a natural but accelerated way. To produce a GMO, specific characteristics can be changed using laboratory-based techniques to delete or alter particular sections of DNA (deoxyribonucleic acid, contains the genetic information, e.g. genes, regulatory elements). An organism's characteristics can also be changed by introducing new pieces of DNA into its genome. These can originate from the same or another, non-related species. The latter results in a transgenic organism, i.e. one that contains genes from a different species. Breeding progress is usually faster and more specific when biotechnological methods are used.

GM techniques can be applied to crops to modify the chemical structure of polymers such as starch, lignin or other fibres. The modification of proteins or metabolites for use in the chemical industry, building industry or in pharmacy is also possible. The use of plant-based antibodies to human or animal diseases has been applied in practice for two decades. The advantage of using GM crops for pharmaceutical purposes is that the agents can be produced in greenhouses or fermenters, and official regimentation is much lower than for field trials. Most varieties of a number of major crops, including soybean, maize and cotton, commonly grown in the USA, Brazil, China, India or elsewhere, have been genetically modified. However, GM crops are usually not well accepted by the general public, and, in Europe, their production in the field is highly restricted. In addition, GMO production is not permitted in organic agriculture. The recently developed gene-editing method CRISPR/Cas9 used in plant breeding is a biotechnical method for cutting out (knocking out) genes without leaving a trace or for specifically altering or adding genes or gene pieces in order to introduce the desired properties. The status of crop varieties produced by this method is the subject of current discussion. The question arises whether these organisms should still be considered genetically modified if only parts of the genes have been cut out or altered without introducing genetic material from other organisms or if genetic material from other species was only temporarily introduced for intermediate breeding steps (e.g. early flowering in trees) and then removed again.

Breeding and genetic modification can be categorized according to the nature of the conferred traits. Input traits are those that affect crop performance without changing the nature of 
the harvested product. Examples include resistance to pests, viruses, bacteria, fungi or insects, tolerance to abiotic stresses (e.g. soil-borne metals, salinity, drought, heat) and a higher nutrient use efficiency resulting in higher yields of biomass or target products.

Output traits change the quality of the crop product itself, e.g. by altering the starch, protein, vitamin or oil composition to improve the nutritional value. This may be, for example, through an increase in vitamins, omega-3 fatty acids or antioxidants, a decrease in saturated fats or an improved amino acid balance. Other output-trait-related targets include an enhanced level of essential minerals ( $\mathrm{Fe}, \mathrm{Zn}$ ), the elimination of allergenic proteins, improved taste, longer shelf life and the introduction of novel food products. Output traits may also focus on the (small-scale) production of biomass for biopharming, sold at premium price.

\subsubsection{Biological Knowledge}

The discipline of biology was established around 1800 as the "science of life". Biological research produces large sets of data on different scales, ranging from genetic information to biodiversity and the interactions between species, landscapes and climates. Biological knowledge is the combination of biological data and the interpretation of its meaning. Traditionally, such data were interpreted by a person; however, today the interpretation of large-scale data sets is only possible with the help of computers due to the sheer volume of data. This is mostly done by bioinformatics - the use of computational and mathematical techniques to store, manage and analyse biological data (Kaminski 2000). A major area of bioinformatic application is the analysis of DNA and protein sequences and structures in order to characterize the linked functions. The term "omics data" is also used to refer to this type of bioinformation. There are data available for genomics, proteomics, metabolomics, ionomics and several other -omics. The term "big data" is also used for large quantities of biological data but can also be applied to other areas than genetic information, such as data for analysing human health and interactions with various factors including nutrition and the environment. Omics data are often used for breeding purposes, e.g. for the identification of genes that code for important traits such as crop resistance to pathogens, and animal health or quality parameters. Big data sets can be used, for example, to describe the pharmacological relevance of particular substances, e.g. those produced by plant cultures, either GM or conventional. This is of great value for a knowledge-driven, biobased economy because it can help to provide practical information for developments in medicinal or food crop production. An example is the use of biobased genomic data for the design of a plant-tissue-based antibody (immune globulin) for the treatment of cancer. For this purpose, the binding specificity of the antibody to its target was calculated from a bioinformatic-based data set (genomic and proteomic data). The designed gene sequence for the antibody was then introduced into tobacco cell culture in fermenters, where the protein (i.e. the antibody) was expressed (for further details, see Ma et al. 2005).

Biological knowledge also includes the understanding of naturally occurring mechanisms (bionics). A prominent example is the so-called lotus effect. This describes the self-cleaning properties of the lotus plant (Nelumbo nucifera) that results from the ultrahydrophobicity of its leaves. Technical application of this mechanism is used for paints, coatings, roof tiles, fabrics and other surfaces that can stay dry and clean themselves. Biologization is the integration of such natural concepts into economic development, the application of biological and life science innovations and the development of products and solutions by means of life sciences. Biologization and digitalization (seen in the example of bioinformatics above) are often considered as convergent and potentially synergetic processes. 


\section{Synthetic Biology}

Synthetic biology goes beyond the application of existing biological mechanisms and knowledge. It uses the tools genetic engineering and biotechnology to construct completely new, not naturally occurring biological functional units or systems with desired properties or remodel existing biological systems for new tasks (Kircher et al. 2017). For example, recent technological advances have enabled scientists to produce new sequences of DNA from scratch. Through the application of modern engineering principles and the use of computers and chemicals, organisms can be designed that are suitable for technical purposes, for example, the direct production of biofuels or precursor chemicals for pharmaceutical drugs. Synthetic biology offers new opportunities in the bioeconomy, e.g. for the supply of products that cannot be produced economically by chemical processes or for which there are no natural synthesis methods (Kircher et al. 2017).

\section{Review Questions}

- What are the major resources used in the bioeconomy?

- How can biological knowledge be applied?

- Describe the energy balance of biomass production through the process of photosynthesis.

- Which plant nutrients are important for biomass formation?

- Which input and output traits are relevant for plant modification? 


\subsection{Biobased Value Chains and Networks}

Ralf Kindervater, Ursula Göttert, and

Dominik Patzelt

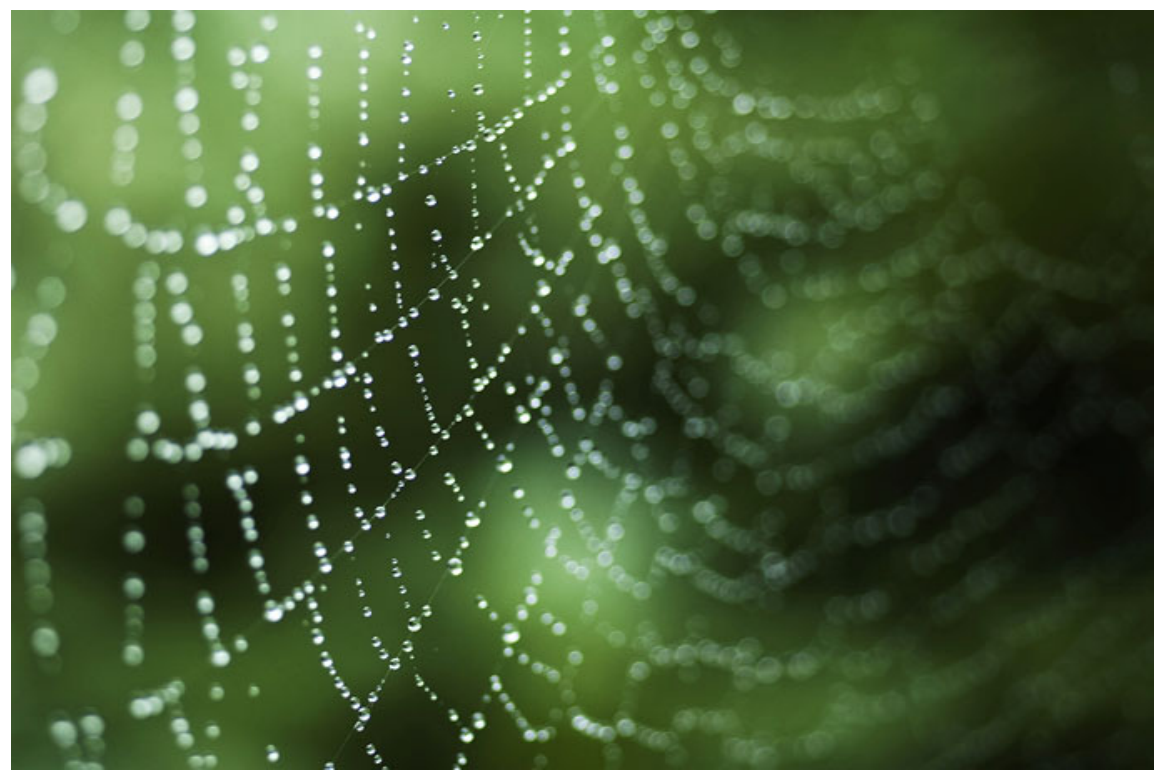

(C) Canned Muffin

\begin{abstract}
In order to describe bioeconomic activities, the term biobased value chain is often used by policymakers (European Commission, A bioeconomy strategy for Europe. Working with nature for a more sustainable way of living. European Commission, 2012; BMBF 2011), organizations (GBS, Communiqué of the global bioeconomy Summit, 2015) and researchers. In the bioeconomy, value chains are built on biological resources and therefore called "biobased". This chapter addresses the fundamental concept of value chains and investigates unique characteristics of biobased value chains.
\end{abstract}

Keywords Value chain; Biobased value chain; Value network; Cascading use; Biorefinery

\subsubsection{Introduction to Value Chain}

There are manifold concepts and notions to describe the relationship and interdependencies among players within an industry sector. For instance, supply chain, (global) value chain, market chain, value web or global commodity chain. While most of these concepts have considerable overlapping meanings and/or can be used interchangeably, in bioeconomy most commonly the term "biobased value chain" is used (Nang'ole et al. 2011; Kaplinsky and Morris 2002).

The first standardized approach to investigate the link between players in agricultural production systems and to visualize their relationship through a metaphorical chain was made by the 
French Institut National de la Recherche Agronomique (INRA) and the Centre de Coopération Internationale en Recherche Agronomique pour le Développement (CIRAD) with their concept of filiere (French for thread) in the 1970s. The concept was developed as an analytical tool to study the organization of farmers and processors (Nang'ole et al. 2011).

In the 1980s Michael E. Porter established the term value chain. He conceptualized the organization of a firm as a system made up of subsystems, each with inputs, transformation processes and outputs (Porter 1985). Each (sub) system involves the acquisition and consumption of resources, i.e. money, labour, materials, equipment, buildings, land, administration and management (Fig. 5.7).

While Porter's value chain definition puts an emphasis on only one actor (the firm), newer conceptions expand the scope of the term to achieve a more holistic picture. This broader conception of the term includes the range of activities and complex interactions of various actors (M4P 2008) and is rather related to the concept of filiére. In a context of worldwide integration, the term global value chains arose (Kaplinsky und Morris 2002).

With respect to these newer conceptions, Kaplinsky and Morris (2002) define value chains as following:

The value chain describes the full range of activities which are required to bring a product or service from conception, through the different phases of production (...), delivery to final consumers, and final disposal after use.

Following this, a value chain generally starts with the extraction or production of a raw material and the logistics to transport it to the first point of processing. Then the chain continues step by step with each following intermediate product until the final product is reached, marketed, sold to the customer and serviced over its lifetime. The visualization usually follows a left-to-right orientation with each step depicted in an arrow-shaped box.

Raw materials such as crude oil have to undergo a large number of transformation steps before they result in the final (e.g. plastic) product. As such, "complete" value chains would be very long and incomprehensible. To avoid this, value chains are often simplified by grouping activities. This makes it easier to read the value chain but also leads to a loss of detail. In Fig. 5.8 a simplified biobased value chain is shown, including primary production, conversion and market. Features of biobased value chains are discussed in Sect. 5.2.2.

Value chains are often also called "valueadded chains". This reflects the fact that, from an economic point of view, there is typically an increase in value with each step applied. The value chain approach allows stakeholders to understand the cost structure and the socioeconomic value of a product in a comprehensive and transparent way.

For additional information about the valueadding process, a value chain may be complemented by a product chain, a process chain and an information flow. Product chains aim to visualize the transformation from the raw material(s) over intermediates to the final product(s). Process chains display the processes which are applied to receive all needed intermediates. Simultaneously, the value-adding activities entail information about economic
Fig. 5.7 The original value chain model of Michael E. Porter (based on Porter 1985)

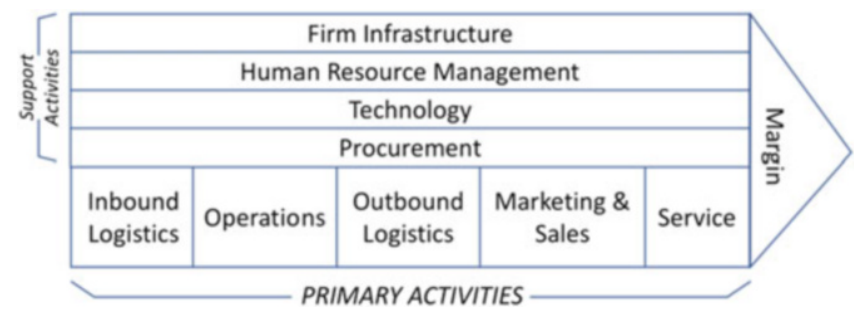




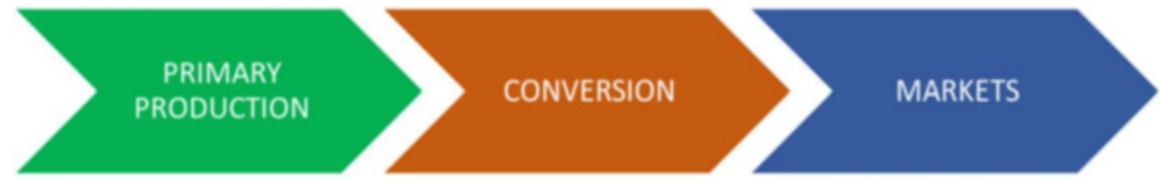

Fig. 5.8 Simplified biobased value chain

figures, social indicators and the environmental impact. An example for biobased plastics production is shown in Fig. 5.9.

As mentioned above, for reasons of simplicity, the value chain has a linear form. For more complex products, such as cars, machines, buildings and packaging solutions, a simple value chain is not optimal for the depiction of the manufacturing procedure, as many different materials derived from different processes are used. Here, it is better to introduce the concept of "components" and define the manufacture of a complex product as the assembly of several components, with the production of each component being shown in a linear value chain. The complete production process can then be illustrated in a so-called value network (or value-added network), which integrates multiple value chains. Figure 5.10 shows the example of a value-added network for the manufacture of biobased car parts and biomethane as fuel.

In the bioeconomy, due to the vast applicability of biobased raw materials, value networks can also be used to illustrate and thus gain a better understanding of the production paths in the manufacture of complex goods from a particular renewable raw material, e.g. wood. Forestry wood consists of several base materials, such as cellulose, lignin, hemicellulose and other chemical substances depending on the type of tree. A value network makes it possible to describe the manufacturing of complex products derived from multicomponent raw materials. It also allows side streams of residual components (e.g. lignin in paper production) to be displayed, which may occur at any stage in the production process. Thus, value networks provide a holistic view of the production process of complex goods and can be used to develop production scenarios (see Sect. 9.2) for a sustainable bioeconomy, following a zero-waste strategy and cradle-to-cradle concepts. A detailed understanding of value networks is also essential to gain the necessary information for successful innovation processes, e.g. in the replacement of fossil by renewable resources. Whenever a raw or intermediate material is replaced, the transition to the next value step has to be evaluated and properly planned. Any misfits may cause a break in a value chain, inhibiting the smooth integration of new raw materials into an existing production process.

The value chain approach is related to the competence of system thinking (see Sect. 4.3) and the central idea of life-cycle assessments (see Sect. 8.3). It attempts to portray the impact of a product on its environment and the interdependencies of production systems.

\subsubsection{Characteristics of Biobased Value Chains}

Bioeconomic concepts focus on the sustainable and efficient use of renewable, biological resources. Cascading use is considered to be a central concept of the bioeconomy, and efforts are taken to apply it to biobased value chains (Odegard et al. 2012). Generally, cascading is about optimizing the functional and consecutive use of biomass with respect to present conditions and future alternative applications. By means of efficiency, cascading aims at the maximization of socioeconomic value given the constraint of resource limitation (Haberl and Geissler 2000). However, the term is interpreted in various ways.

Firstly, it could be understood as an efficient use of biomass for different purposes in time. For instance, the use and recycling of paper including different applications is an already established case.

Secondly, cascading may be considered as the prioritization of high (socioeconomic)-value biomass applications. This means that plant biomass is first used in the food sector to ensure food 

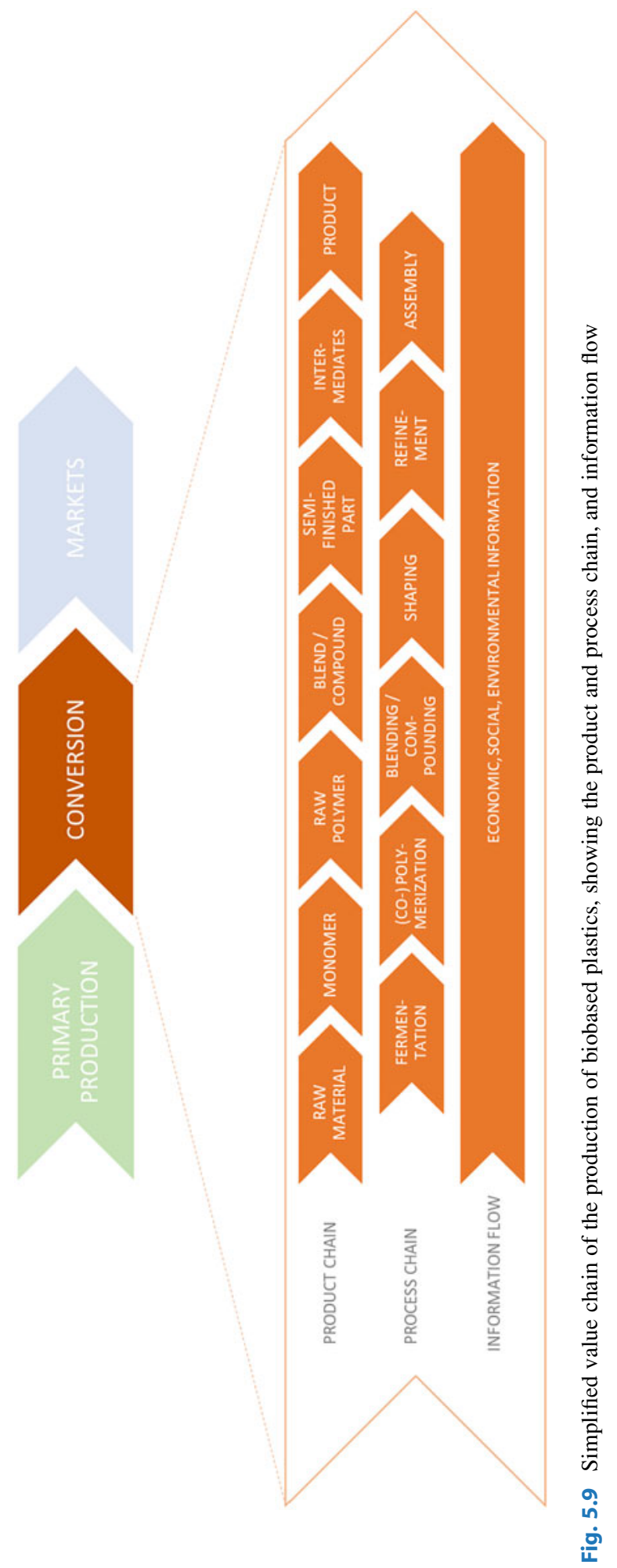


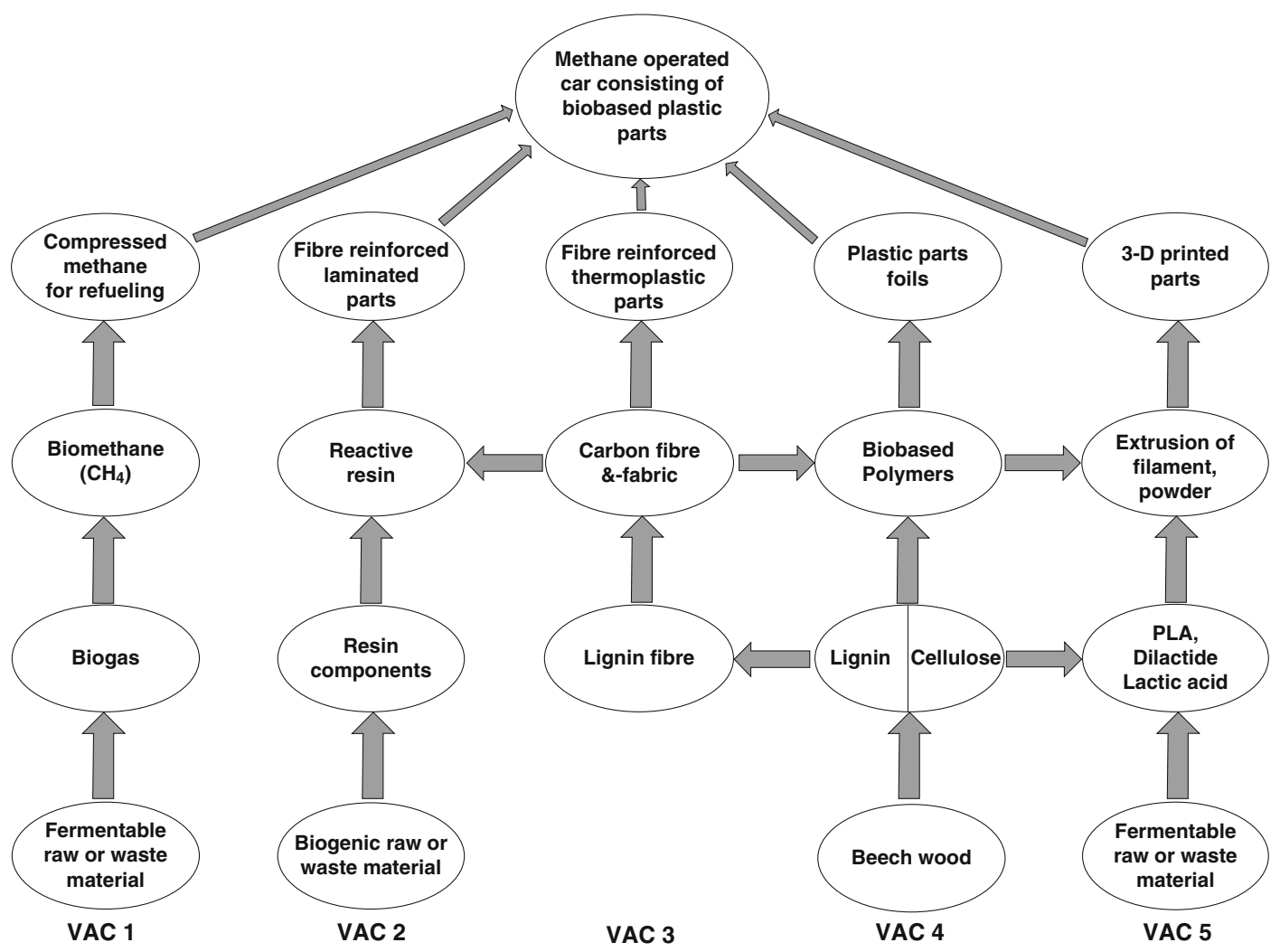

Fig. 5.10 Value network consisting of five value-added chains (VAC) for the manufacture of car parts from biobased plastic and biomethane as fuel (BIOPRO, shown at ACHEMA 2015)

security or for production of pharmaceuticals in the healthcare industry. Sequentially, residual matter is used for feed and/or material, before by-products are finally exploited for energy generation (see Fig. 5.11).

In addition, also biorefining is seen as an application of the cascading approach. In biorefineries biomass serves as a source for several valuable products or functional components through different conversion processes and is thereby used as efficiently as possible. Although it is not a new concept, it has gained attention in recent years. Biorefinery systems differ according to the (1) flexibility to process various types of feedstock, (2) characteristics of the conversion processes and (3) product diversification (Sadhukhan et al. 2014). Some examples are lignocellulosic feedstock biorefinery, whole crop biorefinery and green biorefineries (which use nature-wet biomass), among others (Kamm et al. 2012). In grass refineries, wet grass is converted in a range of products such as plastics, insulation materials, fertilizers and energy (see Box 5.1).

\section{Box 5.1 Grass Refinery}

A grass refinery is an example of green biorefining. In this concept, ideally regionally produced meadow grasses are refined to a range of products including composites, insulation materials, fertilizers and electricity. Following a cradle-to-cradle approach, products can be fully recycled without

(continued) 


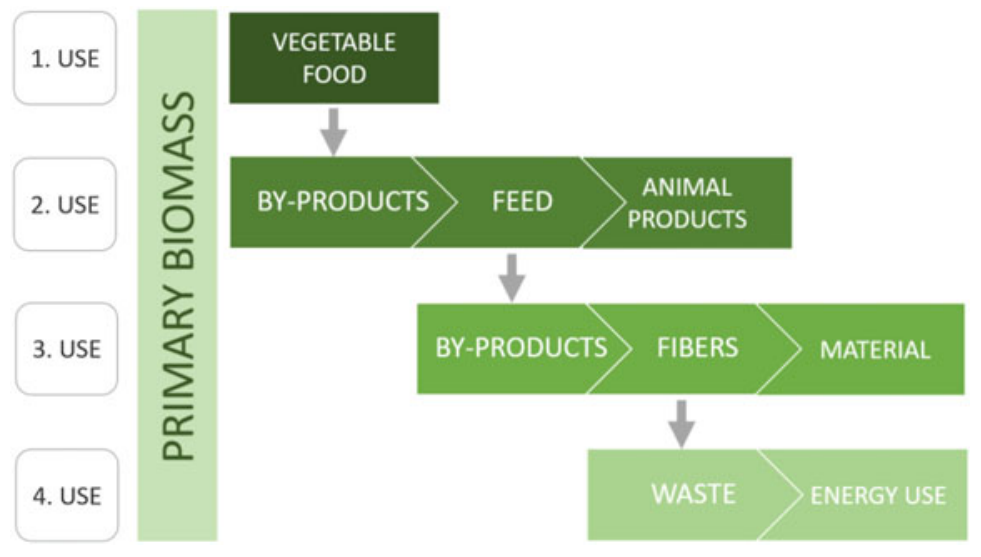

Fig. 5.11 Cascading use of primary biomass

MEADOW GRASS

GRASS REFINERY

GRASSLAND FARMING

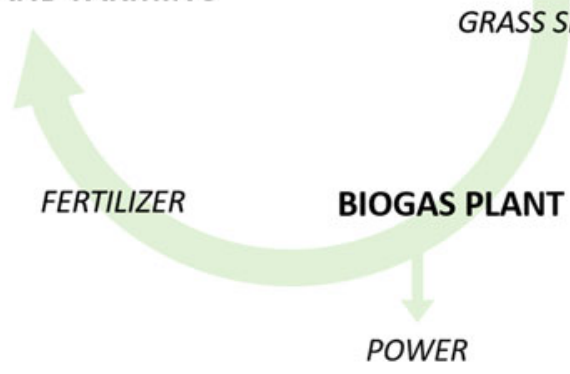

Fig. 5.12 Grass refinery

\section{Box 5.1 (continued)}

generation of waste. Within the production process, materials are used as efficiently as possible and in closed loops. For instance, process biogas and heat are used for heating or drying within the refinery (Fig. 5.12).

Obviously, the introduced interpretations of cascading use are not mutually exclusive and should be perceived complementary in order to ensure the most efficient use of biomass.
Furthermore, the concept of cascading is often seen to be complemented by the principle of circularity (Kovacs 2015). In biobased value chains, it addresses the closing of material and energy flows, transforming linear production processes into circular or closed ones, accordingly reducing the generation of waste.

To establish cascading of biological resources on an economy-wide scale, entire biobased value chains have to be formed and eventually integrated in value networks. The development of new biobased value chains requires cooperation between previously unconnected sectors in 
order to handle the specific characteristics of bioeconomic value chains.

Most of these characteristics are derived from the involvement of primary production of biological resources in the value chains. Especially in forestry or agriculture, production processes are characterized by seasonal patterns, occur decentralized and underlie quality variations due to environmental conditions. In addition, the transportability of biomass is often limited due to its low density and susceptibility to decaying. Accordingly, primary biomass processing has to take place on a regional scale and is characterized by various and divergent players. For instance, in future, so far rarely interacting industrial sectors such as established chemical companies and small-scale farmers will have to cooperate intensively, in order to produce biobased chemicals for an emergent bioeconomy (Berg et al. 2017).

Considering these features, biobased value chains form a strong contrast with continuous fossil-based production processes, and a substantial mind shift will be required in conventional business logics and approaches.

\subsubsection{Examples of Value Chains in the Bioeconomy}

In the following section, three examples of biobased value chains are given, for food, fuel and fibre production. These simplified value chains consist of components aggregating various process and product steps (see Fig. 5.9).

Before milk is distributed to the final customer (Fig. 5.13), multiple processes and product steps are required. For instance, the value chain component "feed production" includes all steps, such as feed crop production, harvest and storage, needed to supply dairy cows with feed. Similar to rearing of cows (dairy cattle farming) and the milk production itself, these processes can follow a large variety of different methods and techniques. The wide variety of approaches in agricultural production systems depends on various factors described in Sect. 6.1.

The value chain of biogas in Fig. 5.14 comprises four components. The feedstock mix depends on the biogas plant and management. Here, energy crops (e.g. corn or miscanthus) are cultivated, including all process steps from soil preparation to harvest. In the biogas plant, biomass is digested by methane-producing anaerobic microorganism. The following component contains all upgrading processes (e.g. purification), preparing the biogas for the market. The distribution component comprises chains visualising logistic, marketing and service.

The value chain of different paper-based materials is shown in Fig. 5.15. This includes forest management to produce wood and the following wood processing steps, such as fibre separation

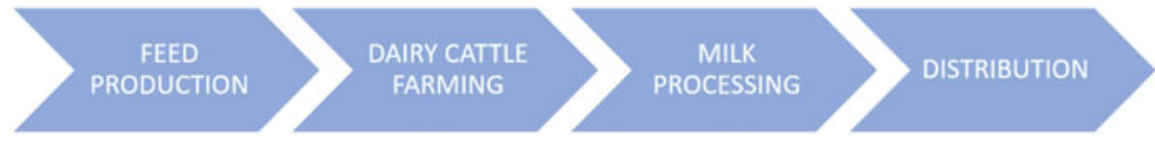

Fig. 5.13 Dairy products value chain

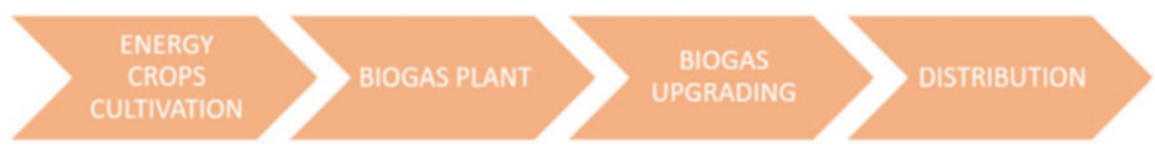

Fig. 5.14 Biogas value chain

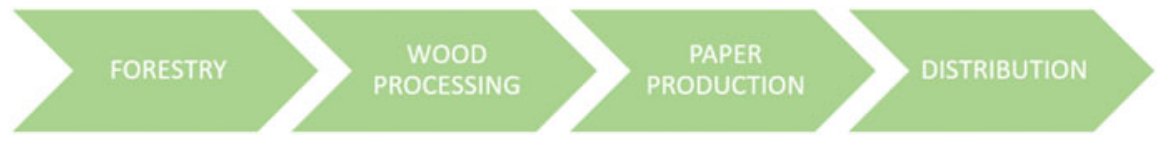

Fig. 5.15 Paper value chain 
(pulping), which is possible by means of different processes. Finally, the separated fibres (pulp) undergo pressing and drying processes in order to remove water from the final paper product.

\subsubsection{Using Value Chains and Value Networks in Technology Transfer and Innovation Support Activities}

Technology transfer activities typically consist of efforts to commercialize research results in cooperation with individual companies. However, the technology transfer officer in charge of the commercialization of a particular product may be unaware of the complete value chain and the exact position of the company concerned along the chain. In a biobased economy, technology transfer and innovation support professionals need to interconnect all parties involved in a particular value network and learn about their individual needs and motivation to shift from fossil to biobased resources. Interactions between members of a value network are typically based on a vendor/purchaser relationship. This slows down the innovation process and often means that biobased components and products enter the market only if they are price competitive.

If economic developers succeed in addressing the needs of all parties in the value chain, highly innovative research and development projects become feasible. Following this approach, individual requirements (e.g. material quantities and qualities) can be addressed. The authors' experience has shown that the integration of all participants of a value chain into $R \& D$ projects can decrease development cycles of biobased products by half.

\section{References}

Berg S, Kirchner M, Preschitschek N et al (2017) Die Bioökonomie als Kreislauf- und Verbundsystem. In: Pietzsch J (ed) Bioökonomie für Einsteiger. Springer, Berlin
BMBF (2011) National research strategy bioeconomy 2030. Federal Ministry of Education and Research (BMBF), Berlin

Demoll (1927) Betrachtungen über Produktionsberechnungen. Arch Hydrobiol 18:462

European Commission (2012) A bioeconomy strategy for Europe. Working with nature for a more sustainable way of living. European Commission, Brussels

FAOSTAT (2014) Food and agriculture organization of the United States - Statistics Division. http://faostat. fao.org/

GBS (2015) Communiqué of the global bioeconomy Summit. Making bioeconomy work for sustainable development. http://go.nature.com/293zhq2. Accessed 25 Jun 2017

Haberl H, Geissler S (2000) Cascade utilization of biomass: strategies for a more efficient use of a scarce resource. Ecol Eng 16:111-121. https://doi.org/10. 1016/S0925-8574(00)00059-8

Kaminski N (2000) Bioinformatics: a user's perspective. Am J Respir Cell Mol Biol. https://doi.org/10.1165/ ajrcmb.23.6.4291

Kamm B, Gruber PR, Kamm M (2012) Biorefineries industrial processes and products. Ullmann's encyclopedia of industrial chemistry. Wiley-VCH, Weinheim, pp 659-683

Kaplinsky R, Morris M (2002) A handbook for value chain research. Institute of Development Studies, University of Sussex

Kircher M, Bott M, Marienhagen J (2017) Die Bedeutung der Biotechnologie für die Bioökonomie. In: Pietzsch J (ed) Biökonomie für Einsteiger. Springer, Berlin, pp 105-128

Kovacs B (ed) (2015) Sustainable agriculture, forestry and fisheries in the bioeconomy - a challenge for Europe. Standing Committee on Agricultural Research - 4th Foresight Exercise. European Commission, Brussels

Lewandowski I, Wilhelm C (2016) Biomasseentstehung. In: Kaltschmitt M, Hartmann H, Hofbauer H (eds) Energie aus Biomasse: Grundlagen, Techniken und Verfahren. Springer, Berlin, pp 77-123

M4P (2008) Making value chains work better for the poor: a toolbook for practitioners of value chain analysis, Version 3. Making Markets Work Better for the Poor (M4P) Project, UK Department for International Development (DFID). Agricultural Development International, Phnom Penh

Ma JKC, Chikwamba R, Sparrow P et al (2005) Plantderived pharmaceuticals-the road forward. Trends Plant Sci. https://doi.org/10.1016/j.tplants.2005.10. 009

Nang'ole E, Mithöfer D, Franzel S (2011) Review of guidelines and manuals for value chain analysis for agricultural and forest products. Occasional Paper 17. World Agroforestry Centre, Nairobi

Odegard I, Croeze H, Bergsma G (2012) Cascading of biomass: 13 solutions for a sustainable bio-based economy. CE Delft, Delft 
Porter ME (1985) Competitive advantage. Creating and sustaining superior performance. The Free Press, New York

Radmer RJ, Kok B (1977) Light conversion efficiency in photosynthesis. In: Trebst A, Avron M (eds) Photosynthesis I: photosynthetic electron transport and photophosphorylation. Springer, Berlin, pp 125-135

Raschke A, Carus M (2012) Industrial material use of biomass basic data for Germany, Europe and the world. Nova-Institute, Hürth
Sadhukhan J, Ng KS, Martinez E (2014) Biorefineries and chemical processes: design, integration and sustainability analysis. Wiley, Chichester. https://doi. org/10.1002/9781118698129

Taiz L, Zeiger E, Moller IM et al (2015) Plant physiology and development, 6th edn. Sinauer Associates, Sunderland

Wilhelm C, Selmar D (2011) Energy dissipation is an essential mechanism to sustain the viability of plants: the physiological limits of improved photosynthesis. J Plant Physiol. https://doi.org/10.1016/j.jplph.2010.07.012

Open Access This chapter is licensed under the terms of the Creative Commons Attribution 4.0 International License (http://creativecommons.org/licenses/by/4.0/), which permits use, sharing, adaptation, distribution and reproduction in any medium or format, as long as you give appropriate credit to the original author(s) and the source, provide a link to the Creative Commons license and indicate if changes were made.

The images or other third party material in this chapter are included in the chapter's Creative Commons license, unless indicated otherwise in a credit line to the material. If material is not included in the chapter's Creative Commons license and your intended use is not permitted by statutory regulation or exceeds the permitted use, you will need to obtain permission directly from the copyright holder. 